\title{
Roberts uterus: a rare congenital anomaly
}

\section{Nagendra Sardeshpande, Pratima Chipalkatti, Jainesh Doctor*}

Department of Obstetrics and Gynecology, Bombay Hospital Institute of Medical Sciences, Mumbai, Maharashtra, India

Received: 12 October 2017

Accepted: 08 November 2017

\section{*Correspondence:}

Dr. Jainesh Doctor,

E-mail: jainesh_doctor@yahoo.co.in

Copyright: () the author(s), publisher and licensee Medip Academy. This is an open-access article distributed under the terms of the Creative Commons Attribution Non-Commercial License, which permits unrestricted non-commercial use, distribution, and reproduction in any medium, provided the original work is properly cited.

\section{ABSTRACT}

A 23-year-old girl presented with severe cyclical lower abdominal pain during menstruation since menarche, which had increased since the last 4 years. Transabdominal ultrasound showed adnexal mass with no internal vascularity; MRI reported it as bicornuate uterus with one non-communicating right uterine horn with haematometra. On hysteroscopy there was evidence of septate uterus communicating only to the left ostia. Ultrasonography-guided hysteroscopic resection of septa with drainage of haematometra was done. Patient is presently asymptomatic.

Keywords: Congenital anomaly, Robert's uterus

\section{INTRODUCTION}

Mullerian duct anomalies have an incidence of $0.1-3.5 \% .^{1}$ Commonly reported anomalies are septate, arcuate, didelphys, unicornuate or hypoplastic uteri. The American Fertility Society (AFS) classification organises MDAs according to major uterine anatomic defect and allows for standardized reporting methods. Septate uterus (AFS Class V) is the most common, resulting from incomplete resorption of the medial septum after complete fusion of the Mullerian ducts has occurred; variations exist like complete, partial and segmental. The complete septum extends from the fundal area to internal os and divides the endometrial cavity into 2 components and is often associated with a longitudinal vaginal septum. The most common presenting symptoms are dysmenorrhea, dyspareunia, primary or secondary infertility, pregnancy loss and obstetric complications.

\section{CASE REPORT}

A 23-year-old unmarried girl came with complains of severe dysmenorrhea since menarche, with increasing severity since last 4 years. She had regular menstrual cycles. On examination her secondary sexual characters were normal. She had mild pallor, marked lower abdominal tenderness but no palpable lump, and normal external genitalia. She had undergone operative laparoscopy for acute appendicitis during which right salphingectomy was done for incidental hematosalphinx. She had also received prophylactic AKT in view of query pelvic Koch's. Exploratory laparotomy was done for acute intestinal obstruction with multiple adhesions with ileal stricture and meckles diverticulitis. Multiple ultrasonographic examinations over the years had reported various diagnosis including complex adnexal mass, broad ligament fibroid with cystic degeneration, exophytic fibroid, polyp etc. CT scan was suggestive of splitting of endometrial cavity, query bicornuate uterus/broad ligament fibroid, with normal urinary syetem/bilateral kidney-ureter-bladder normal. MRI reported it as bicornuate uterus with a noncommunicating right uterine horn with haematometra and mild periuterine fluid and adhesion. On laparoscopy externally, the uterus appeared to have a bicornuate appearance with distended right horn 1.5 times larger than left horn. A large right adnexal mass was adherent to the omentum, bowel and the anterior abdominal wall; right ovary and fallopian tube were not seen. The left fallopian tube and ovary appeared normal. In the process 
of release of the adhesion there was accidental puncture of the adnexal mass with extravasation of chocolate coloured fluid, an evidence of endometriosis. On further dissection to separate the bladder from the uterus, accidental bladder injury occurred. On inspection of bladder mucosa there was evidence of endometriotic tissue invading through it. The bladder mucosa with the endometriotic invasion was excised and sent for histopathological evaluation.

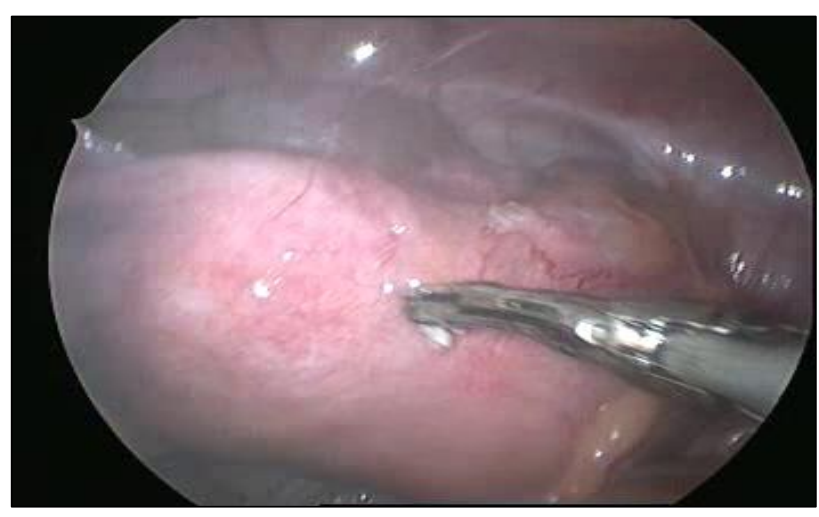

Figure 1: Bicornuate appearance of the uterus.

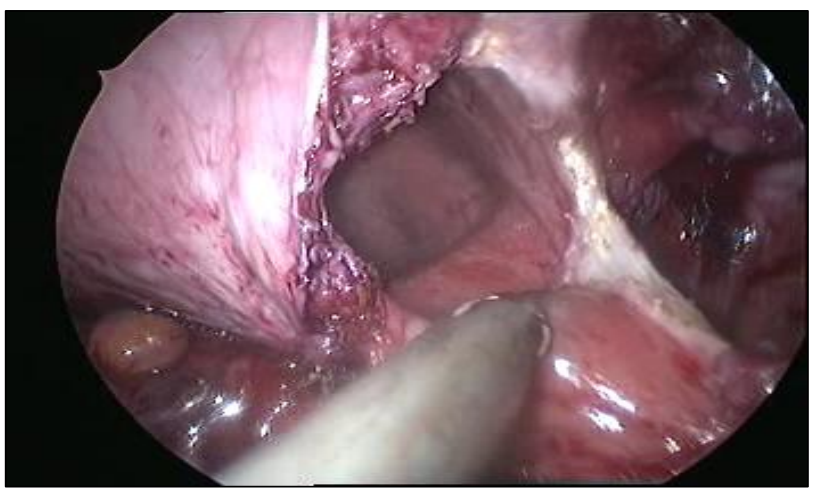

Figure 2: Bladder endometriosis.

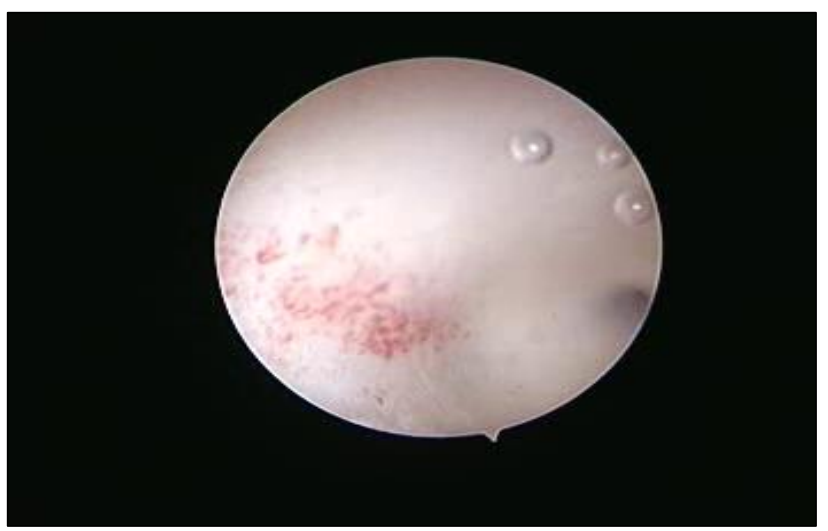

Figure 3: Hysteroscopic small cavity with visualization of left ostia.

Hysteroscopy was done to visualize the uterine cavity. There was evidence of septate uterus with a small cavity communicating to the only seen left ostia. Resectoscope was introduced and septal resection was attempted. On check hysteroscopy the cavity had enlarged but the right ostia could not be visualized. Futher surgical correction was aborted and an intrauterine catheter was kept in situ for 5 days with $10 \mathrm{ml}$ saline distention. The patient was given three cycles of gonapeptidyl injections starting immediately post-surgery. The bladder biopsy was reported as bladder wall endometriosis. After completion of the course, she had normal menses. The next menses however she had recurrence of severe dysmenorrhea. Repeat USG was done which again detected presence of septum, with a collection beyond it in the right horn of the uterus. The patient underwent ultrasound guidedhysteroscopic resection of the septum in which the collection was confirmed to be a haematometra. Postresection normal intra-uterine cavity with endometrium was noted. A Foley's catheter with saline distention was placed in the right horn of uterus for 4 days. Relook hysteroscopy done after 4 months showed thickening of the right lateral wall of uterus with irregular endometrium. The patient then had normal menstrual cycles and is asymptomatic till date on cyclical OC pills. Repeat ultrasonography after 6 months was suggestive of a normal uterus with a normal endometrial lining.

\section{DISCUSSION}

Robert's uterus or asymmetric septate uterus is a rare type of Mullerian duct anomaly and a variant of septate uterus (class V, American Society for Reproductive Medicine Classification), with very few cases of this variant being reported. ${ }^{2,3}$ It was first reported by Robert in 19704.This condition is characterized by complete uterine septum dividing the endometrial cavity asymmetrically resulting in a non-communicating hemi-uterus with one blind horn causing haematometra and one communicating hemiuterus with a single cervix and a normal extrauterine morphology. On laparoscopy or laparotomy, the uterus shows normal fundal contour. As a result, there is obstruction to menstrual flow in one cavity, resulting in haematometra - the cause of cyclical post-menarcheal dysmenorrhea. It is usually accompanied by haematosalpinx and sometimes even endometriosis. Investigations done include ultrasonography, MRI pelvis, Hysterosalphingography and hysteroscopy with laparoscopy. The urinary system i.e. kidneys, ureters, bladder also need to be evaluated for anomalies by USG/CT scan, as they area known association.

MRI provides excellent tissue characterization helping in reliably differentiating septate from bicornuate uterus and also in diagnosing asymmetric septate uterus and is the gold standard investigation. ${ }^{5-7}$ Coronal T2W images of MRI are ideal for demonstrating the uterine septum dividing the endometrial cavity asymmetrically along with the blind ending cavity and haematometra. T1W images show the haematometra and haematosalpinx as bright fluid in the endometrial cavity and dilated fallopian tube. Surgery can be done by open or minimally invasive 
method; definitive surgery involves drainage of hematometra and excision of blind non-communicating hemiuterus taking care to maintain integrity of functional communicating hemiuterus and cervix..$^{8,9}$

\section{CONCLUSION}

Prompt early diagnosis and surgical correction are essential to avoid future morbidity due to endometriosis. Few cases have reported successful pregnancy after endometriectomy in these cases. ${ }^{10}$ Although a rare complication of pregnancy in the non-communicating half of the uterus caused by transperitoneal migration of sperms has been reported. ${ }^{11}$

Funding: No funding sources Conflict of interest: None declared

Ethical approval: Not required

\section{REFERENCES}

1. Acién P. Incidence of Mullerian defects in fertile and infertile women. Hum Reprod 1997;12(7):1372-6.

2. Capito C, Sarnacki S. Menstrual retention in a Robert's uterus, J Pediatr Adolesc Gynecol. 2009;22(5):e104-6.

3. Benzineb N, Bellasfar M, Merchaoui J, Sfar R. Robert's uterus with menstrual retention in the blind cavity. J Gynaecol Obstet Biol Reprod. 1993;22(4):366-8.

4. Gupta N, Mittal S, Misra R. A unique congenital mullerian anomaly Robert's uterus. Arch Gynaecol Obstet. 2007;276(6):641-3.
5. Behr SC, Courtier JL, Qayyum A. Imaging of müllerian duct anomalies. Radiographics 2012;32:E233-50.

6. Marcal L, Nothaft MA, Coelho F, Volpato R, Iyer R. Mullerian duct anomalies: MR imaging. Abdom Imaging. 2011;36(6):756-64.

7. Bermejo C, Ten MP, Cantarero R, Diaz D, Pérez Pedregosa J, Barrón E. Three-dimensional ultrasound in the diagnosis of Mullerian duct anomalies and concordance with magnetic resonance imaging. Ultrasound Obstet Gynecol. 2010;35(5):593-601.

8. Takeuchi H, Sato Y, Shimanuki H, Kikuchi I, Kumakiri J, Kitade M, Kinoshita K. Accurate preoperative diagnosis and laparoscopic removal of the cavitated non-communicated uterine horn for obstructive Mullerian anomalies. J Obstet Gynaecol Res. 2006;32(1):74-9.

9. Perino A, Chianchiano N, Simonaro C, Cittadini E, Endoscopic management of a case of complete septate uterus with unilateral hematometra. Human Reprod. 1995;10(8):2171-3.

10. Vural M, Yildiz S, Cece H, Camuzcuoglu H. Favourable pregnancy outcome after endometrectomy for a Robert's uterus. J Obstet Gynaecol. 2011;31(7):668-9.

11. Chandra M, Pathak V. Pregnancy in noncommunicating half of septate uterus. J Obstet Gynaecol India. 2012;62(1):31.

Cite this article as: Sardeshpande N, Chipalkatti $\mathrm{P}$, Doctor J. Roberts uterus: a rare congenital anomaly. Int J Reprod Contracept Obstet Gynecol 2017;6:5657-9. 